譄lnformação

v. 1, n. 2

jul./dez. 2019

E-ISSN: $2674-6549$
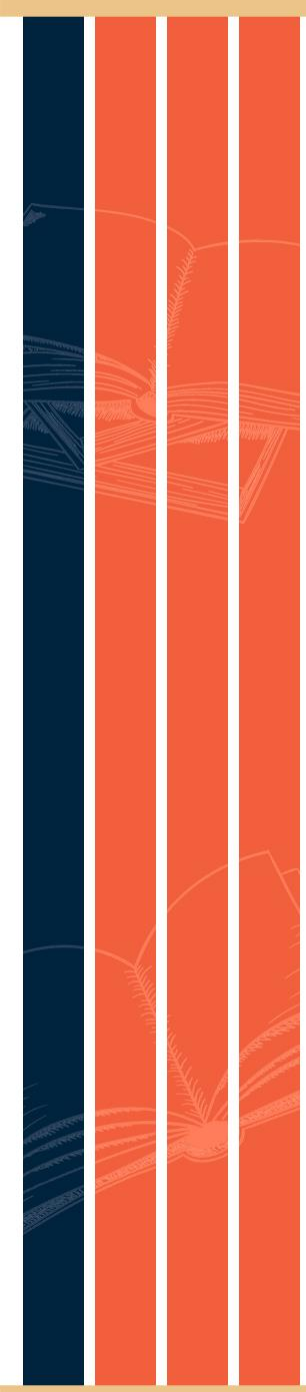

Submissão: $27 / 02 / 2019$ Aprovação: 29/08/2019

\section{EDUCAÇÃO PELA CULTURA EM ARAÇUAÍ: UM PROCESSO DE REINVENÇÃO DA RODA}

\author{
EDUCATION FOR CULTURE IN ARAÇUAÍ: A WHEEL \\ REINVENTION PROCESS
}

Fábio Júnio Mesquita ${ }^{1}$
Karla Cunha Pádua

\title{
RESUMO
}

Este trabalho busca conhecer como a pedagogia da roda se entrelaça à cultura popular no processo de aprendizagem dos/as jovens participantes dos projetos do Centro Popular de Cultura e Desenvolvimento (CPCD), em Araçuaí, município do Vale do Jequitinhonha, em Minas Gerais. Com interesse em pensar novas propostas para a educação de jovens, este estudo exploratório se baseou em pesquisa bibliográfica e documental. Para o propósito deste artigo, foram acessados sites institucionais do CPCD e analisadas produções de autores que colocam em diálogo o tema das pedagogias e das culturas juvenis. Como pressupostos teóricos, nos embasamos na perspectiva pedagógica Freiriana e na ideia de que existem diferentes formas de ser jovem no Brasil contemporâneo, por isso falamos em juventudes no plural. As análises apontaram que, na pedagogia da roda, a cultura é fundamental para atingir a educação proposta pelo CPCD. A prática de compartilhamento de ideias e valorização das juventudes que participam dos projetos, e que acontece na pedagogia da roda, se mostra uma alternativa para educadores/as que buscam outras metodologias para a construção de processos educacionais permanentes junto aos/às jovens.

Palavras-chave: Educação Permanente. Juventudes. Pedagogia da roda. Cultura Popular local. CPCD.

\begin{abstract}
This paper seeks to know how the pedagogia da roda - round pedagogy - intertwines with popular culture in the learning process of young people participating in the projects of the Centro Popular de Cultura e Desenvolvimento - Popular Center of Culture and Development - (CPCD) in Araçuaí, Vale do Jequitinhonha, Minas Gerais. With an interest in thinking about new proposals for youth education, this exploratory study was based on bibliographic and documentary research. For the purpose of this article, the CPCD's institutional websites were accessed and productions of authors who put in dialogue the theme of pedagogies and youth cultures. As theoretical assumptions, we are based on the Freirean pedagogical perspective and on the idea that there are different ways of being young in contemporary Brazil, that is why we talk about youths in the plural. The analysis indicated that, in the round pedagogy, culture is fundamental to achieve the education proposed by the CPCD. The practice of sharing ideas and valuing the youths
\end{abstract}

${ }^{1}$ Mestrando Educação pela Universidade do Estado de Minas Gerais (UEMG). Graduado em Pedagogia pela Faculdade de Ciências Sociais Aplicadas de Belo Horizonte (FACISABH). Lattes: http://lattes.cnpq.br/5632599889885214. E-mail: fabiojmesquita@outlook.com.

${ }^{2}$ Pós-Doutora pela Universidade Federal de Ouro Preto (UFOP) e Doutora em Educação pela Universidade Federal de Minas Gerais (UFMG), com período sanduíche em Instituto de Ciências Sociais da Universidade de Lisboa. Graduada em Ciências Sociais Universidade Federal de Minas Gerais (UFMG). Professora da Universidade do Estado de Minas Gerais (UEMG) Lattes:

http://lattes.cnpq.br/0070726136449085. E-mail: kcpadua@yahoo.com.br. 
who participate in the projects, which happens in the round pedagogy, is an alternative for educators who seek other methodologies for the construction of permanent educational processes with young people.

Keywords: Permanent Education; Youths; Round Pedagogy; Local Popular Culture; CPCD.

\section{INTRODUÇÃO}

A Pedagogia da Roda é materializada no círculo que reúne pessoas de diferentes idades, sexos, etnias, extratos sociais e níveis de escolaridade com um único propósito: aprender permanentemente, enquanto são fortalecidos os laços culturais que identificam aquele grupo, reconectando-os aos seus antecessores. Na roda, o diálogo e a não-exclusão são os meios para se resolver problemas, propor atividades e sugerir mudanças. Em roda, cada sujeito possui uma maneira diferente de ver a realidade que o cerca daquele lugar no qual está posicionado, e por meio da horizontalidade que é construída, todos sabem que seu ponto de vista importa, sua fala interessa para que ações sejam pensadas e transformadas (CPCD, 200-?b).

Assim, a pedagogia da roda se transformou no ponto de partida do Centro Popular de Cultura e Desenvolvimento - CPCD para toda ação a ser desenvolvida, conciliando a resolução de problemas às construções de saberes e práticas. Também é utilizada para refletir e avaliar o processo, a fim de aperfeiçoar o projeto para fazer futuras aplicações com maior eficácia e menor custo de problemas e inovações criativas, ao passo que permite ao/à educando/a e educador/a participarem coletivamente.

O interesse pelas juventudes é o mote deste trabalho. Desde 2011, o cenário da educação brasileira indica que aproximadamente 2,8 milhões de crianças e jovens estão fora da escola (ROITMAN; RAMOS, 2011), não muito diferente daquilo mostrado pelo censo escolar de 2016, indicando a urgência da educação e a necessidade de buscar um ensino de qualidade, que ofereça uma educação que os jovens queiram e que os prepare para a autonomia (ROITMAN; RAMOS, 2011). No que tange às juventudes, existem grandes esforços para compreender melhor esta fase da vida (PAIS, 2009), a cultura juvenil (DAYRELL; GOMES, 2002), as relações e outros pontos relevantes. 
A partir de Nonato et al. (2016), entendemos que é necessário conhecer as múltiplas pedagogias das juventudes, que corroborem para práticas sociais emancipatórias e oportunize novas trajetórias visando o desenvolvimento humano. Assim, o foco de nosso estudo é a pedagogia da roda como uma dessas pedagogias que contemplam a autonomia dos estudantes.

Mas qual a relação entre a Pedagogia da Roda e as juventudes? Por qual motivo ela poderia ser do interesse dos jovens? Essas questões foram indagadas por nós, e ao encontro delas tomamos conhecimento de uma iniciativa da plataforma Porvir, intitulada Nossa Escola em (Re)Construção, que pesquisou, em 2016, jovens de todos os estados do país. Nessa pesquisa foi identificado que os jovens optam por rodas de conversa e projetos como possibilidade de desenvolvimento de competências, sendo os recursos mais sugeridos (PORVIR, 2016, p. 47).

Este formato considerado mais efetivo para a aprendizagem se contrapõe à sala de aula tradicional com carteiras enfileiradas. No entanto, rodas de conversa que não contribuam para a formação dos jovens é de pouca utilidade para a escola. Desse modo, a pesquisa se torna relevante para atender a demanda das juventudes, para encontrar novas pedagogias a serem utilizadas por educadores/as e trazerem resultados, inclusive, para gestores/as educacionais, atendendo aos âmbitos social, profissional e acadêmico.

Para seguir com a leitura, salientamos dois pontos importantes. Primeiramente, esse estudo busca apresentar outra proposta de trabalho a ser desenvolvida com os jovens, não pretendendo ser uma receita ou conter recomendações prontas para inovações em sala de aula, mas um convite ao repensar das próprias práticas, a partir de outra possibilidade. Em segundo lugar, concordamos que não se trata de um modelo de juventude, mas de juventudes, no plural. Existem diferentes formas de ser jovem, portanto, esse é outro fator a ser considerado ao longo deste texto.

O trabalho está divido em três partes: Inicialmente, trazemos a introdução, onde tecemos nossa proposta de pesquisa. Após esta apresentação, abordamos de maneira sucinta o histórico do CPCD, mencionando os projetos sociais em Araçuaí. A metodologia se encontra na terceira parte, onde ressaltamos a importância da 
pesquisa exploratória para conhecimento da pedagogia da roda e da bibliográfica para levantamento das informações desse trabalho. Na quarta parte, caminhamos para a exposição da Pedagogia da Roda que está presente nos projetos do CPCD e em seu cotidiano, desde que começaram a conjugar o verbo "paulofreirear". Ainda nesta parte, discutimos a valorização da cultura que cada jovem traz consigo nesta proposta de roda e tratamos brevemente. E, nas palavras finais, encerramos com as nossas considerações que buscam propor questões a serem investigadas em trabalhos futuros.

\section{BREVES NOTAS SOBRE O CENTRO POPULAR DE CULTURA E DESENVOLVIMENTO 3 , O CPCD}

No final da década de 90, a convite da gestão municipal, chegava o CPCD, em Araçuaí, no médio Jequitinhonha-MG. Incumbido da tarefa de promover o desenvolvimento humano no município, a instituição dedicou atenção especial às juventudes, propondo projetos educacionais e capacitações profissionais que se utilizam da pedagogia da roda e da cultura popular, visando, dentre outros objetivos, minimizar o processo migratório dos jovens para outros municípios à procura de emprego formal ou para o corte de cana. Esse trabalho da instituição, que acontece no âmbito da educação não escolarizada, possui interface com a educação escolar (escolas municipais e estaduais) e pretende contribuir para o êxito dos jovens, com instrução educacional e profissional para o mercado de trabalho e para a vida.

O CPCD é uma Organização Não Governamental - ONG, fundada em 1984 por Tião Rocha ${ }^{4}$, que está vinculada ao Terceiro Setor $^{5}$ (de natureza privada e função social pública), "para atuar nas áreas de Educação Popular de Qualidade e Desenvolvimento Comunitário Sustentável, tendo a cultura como matéria prima e instrumento de

${ }^{3}$ A partir dessa parte do texto será adotada a sigla CPCD, para se referir à instituição.

${ }^{4}$ Para apresentá-lo recorremos ao site do projeto Arasempre (201-?), extraindo de lá suas próprias palavras: "Tião Rocha é meu nome, Sebastião é apelido. Ninguém me chama pelo apelido. Sou antropólogo por formação acadêmica, educador popular por opção política, folclorista por necessidade, mineiro por sorte e atleticanos por sina".

${ }^{5}$ O Terceiro Setor é composto pelas organizações de iniciativa privada, sem fins lucrativos e que prestam serviços de caráter público, como são o caso de ONGs, associações comunitárias, fundações, etc. 
trabalho, pedagógico e institucional" (CPCD, 200-?a). Segundo informações disponíveis no site do CPCD, a ONG foi criada a partir do desejo e crença "que era possível criar um espaço onde as crianças pudessem de fato 'ser criança' e onde o brincar fosse a primeira 'sementinha' para o estar junto, o organizar-se e o ser feliz" (CPCD, 200-?a), o que acabou por dar o nome de Sementinha ao primeiro projeto do CPCD, pensado como uma escola em baixo de uma árvore - um pé de manga.

O CPCD possui diversos projetos no Brasil e no mundo e, em Araçuaí, acontecem seis destes projetos, todos com foco na educação e desenvolvimento das potencialidades dos integrantes, a saber: Arassussa - Araçuaí Sustentável; Cinema Meninos de Araçuaí; Fabriquetas; Meninos de Araçuaí (Coral); Ser Criança; e Sítio Maravilha. Todos estes projetos compõem uma plataforma de transformação social baseada no "[...] incentivo ao protagonismo dos jovens, na criação e gestão de pequenos empreendimentos, [...]; o trabalho com famílias da zona rural para construir quintais autossuficientes e produtivos;" e também, no envolvimento de jovens e adultos para "a formação de agentes comunitários e educadores, que levam e aplicam essas tecnologias em todo canto da cidade [...]" (ARASEMPRE, 201-?). Em suas muitas frentes de trabalhos, o CPCD mantém a cultura como princípio e a educação como fim, utilizando da pedagogia da roda para nortear seus trabalhos.

\section{METODOLOGIA}

Por ser parte de uma pesquisa em andamento, os dados que serão aqui apresentados são de cunho teórico, coletados por meio de consultas e leituras a livros, periódicos, sites e estudos que tratam sobre a pedagogia da roda e o CPCD. Ao buscarmos conhecer a literatura produzida nos deparamos com pouquíssimos trabalhos que se aproximaram de uma discussão a respeito desta pedagogia. Posto isto, partimos para uma pesquisa exploratória para investigar esta pedagogia através de relatos e teorias publicadas em livros na internet.

O objetivo específico desta etapa da pesquisa se tornou o de conhecer e analisar as principais contribuições escritas sobre esta pedagogia, com vistas a abrir caminhos à compreensão da pedagogia da roda. Dito isto, trata-se de uma pesquisa 
exploratória, de caráter qualitativo. Tendo sido realizada por meio de pesquisa bibliográfica e documental, que Ruiz (1985) conceitua como o exame de escritos para levantamento e análise do que já se produziu sobre determinado assunto.

Este momento da pesquisa foi marcado por esta busca de informações, ainda em um momento embrionário da pesquisa: o planejamento. Nesta fase, buscou-se o máximo de informações sobre o assunto e o seu fichamento, conforme nos ensina Luna (2011), no que tange a como iniciar o levantamento bibliográfico e as revisões de literatura. Assim, foi feita a seleção dos materiais a serem analisados; localizando e identificando o material potencialmente relevante; realizando resumos e fichamentos; e organizando as citações e referências pertinentes, que ocorreu ao longo da reescrita do projeto de pesquisa para o mestrado, dando origem às informações que apresentaremos mais adiante.

Após a revisão de literatura, o trabalho foi elaborado tomando Tião Rocha como teórico da pedagogia da roda, com auxílio dos dois sites do CPCD: o site institucional do CPCD, que atende aos propósitos da ONG de um modo geral; e o site da Plataforma Arasempre, que é especificamente do CPCD em Araçuaí. Paulo Freire é o teórico da cultura e educação com o qual este trabalho dialoga. No tocante aos jovens envolvidos na instituição, Juarez Dayrell foi a quem recorremos para junto a outros autores desenvolvermos este trabalho.

\section{ANÁLISE E INTERPRETAÇÃO DOS RESULTADOS}

Vários são os teóricos que acreditam na possibilidade de educação/formação por intermédio das contribuições coletivas de diferentes atores neste processo. Aqui, abordaremos a pedagogia da roda, de Sebastião Rocha (2000), mas ressaltamos a existência de outras propostas, como a aprendizagem por heterogênese (GUATARI, 1993), que é formado a partir do já sabido e da novidade que é conhecida através do grupo; a inteligência Coletiva (LÉVY, 1998), que defende que não há quem "pense" sozinho, mas que pensamos em circuito de rede de conhecimento; a Documentação Narrativa de Experiências Pedagógicas, para além dos registros escritos das narrativas, Daniel Suárez e Liliana Ochoa (2005) acreditam que a práxis da escrita permite que o 
professor acesse palavras que não se consegue sozinho, sendo essencial para isso a relação com o coletivo; e os Círculos de Cultura, de Paulo Freire (1992). Não se tratando de estágios de evolução entre eles, mas de métodos diferentes para acessar outras maneiras possíveis de aprender coletivamente.

Dentre todos esses teóricos e suas teorias, são as contribuições de Paulo Freire as que mais se relacionam com a pedagogia da roda, tanto pelos Círculos de Cultura como pelas Pedagogias do Oprimido e da Autonomia. Visto que as práticas de Tião Rocha trazem em seu contexto este educador em especial, que é conjugado como o verbo "paulofreirear", cunhado e aplicado no CPCD, evidencia-se a influência na práxis dos envolvidos na instituição. Acreditando que discutir protagonismo do jovem, junto ao próprio jovem, é um processo de conscientização, é trazer ao oprimido a consciência de que ele pode mais (FREIRE, 2015). Essa relação do CPCD com Freire surge em uma conversa com algumas professoras que estavam experimentando outros modos de fazer a educação - a saber, aulas na rua, embaixo de uma árvore - na ocasião uma comentou:

- "Engraçado, eu pensei que os meninos fossem virar uma fumaça, lá debaixo da árvore, pois na sala eles só ficam falando "tia, posso ir no banheiro", "tia, posso ir lá fora", "tia..."; eu pensei 'lá fora, eles vão sumir'. Aconteceu, porém um negócio engraçado: eles ficaram mais atentos do que normalmente. Eu não precisei chamar a atenção, nem gritar. Eles estavam mais disciplinados do que quando estão na sala. Parece que havia uma disciplina assim... na cabeça deles..."

- Disciplina como, professora? Provocamos nós.

- "Disciplina... assim... disciplina...intelectual", ela conseguiu sintetizar depois de algum tempo. Foi a oportunidade que queríamos. Tomamos um livro, abrimos e entregamos para esta professora ler. Ao ler, comentou:

- "Hum, cansei de ler este cara e nunca entendi nada... hum! Paulo Freire..." E então leu o seguinte: “... só há aprendizagem quando há disciplina intelectual, vontade, interesse..." - Pronto! Professora, pode devolver o livro! Dissemos-lhe.

- “Ah, então é isso?! Não sabia!”, concluiu ela.

Naquele momento, "descobrimos a pólvora": Paulo Freire não é para ser lido, mas sim para ser praticado. E foi dessa experiência que brotaram, como que naturalmente, os princípios metodológicos de nossa proposta:

- Como praticar Paulo Freire? 
- Como transformar seus conceitos em atividades?

- E o mais elementar de seus conceitos, a coluna vertebral de sua metodologia: ação - reflexão - ação. Como fazer isso?

Pronto! Acabamos de descobrir (ou reinventar) a roda. A roda seria o início e o fim de nossos trabalhos. Seria o nosso jeito de praticar "ação-reflexãoação". (ROCHA, 2000, p. 26)

Rocha (2000) narra assim o surgimento do interesse pela roda e a consolidação da prática freireana no cotidiano do CPCD. A partir de então, começava a florescer a Pedagogia da Roda. Proposta que é realizada por intermédio do círculo, "[...] a figura geométrica que melhor sintetiza uma relação de equilíbrio e harmonia" (ROCHA, 2000, p. 27), para isto é necessário que a roda não apresente irregularidades: todos precisam estar acomodados e confortáveis; todos devem conseguir ver os demais participantes da Roda; não existe alguém que não tenha algo a aprender com os demais. Enfim, trata-se de um espaço de colaboração de saberes entre pessoas com diferentes culturas, mas em relações de igualdade, e que guarda proximidades claras com os Círculos de Cultura, de Paulo Freire (1992).

Sabendo que na Roda emergem diferentes expressões de cultura, e que todas devem ser consideradas. Recorremos à outra obra de Tião Rocha (1996), em que observou diferentes formas culturais na sociedade em que vivemos, delas elenca as três principais, sendo que a cultura popular é o foco dos trabalhos no CPCD:

Dentro do conceito de 'sociedade civilizada' (da qual fazemos parte), ao contrário da 'sociedade ágrafa' (sem escrita) da qual fazem parte os indígenas brasileiros, por exemplo, coexistem e podem ser analisadas, normalmente, três formas culturais distintas:

1 - cultura erudita (ou acadêmica) que é a maneira de viver de um indivíduo (ou grupo social) orientada, dirigida ou, até mesmo, imposta por uma instituição (Estado, Escola ou Igreja, por exemplo). Seus valores são dirigidos e, em geral, permanentes.

2 - cultura de massa (ou de consumo) que é a maneira de viver de um indivíduo (ou grupo social) orientada, dirigida ou, até mesmo, imposta pelos modismos e necessidades imediatas criadas e/ou estimuladas pelos meios de comunicação em geral (Rádio, Televisão, Jornais, Revistas, etc.). Seus valores são dirigidos e, em geral, temporários e mutáveis. 
3 - cultura popular (ou folclórica) é a maneira de viver de um indivíduo (ou grupo social) não dirigida por qualquer instituição (como Estado, Escola ou Igreja) e, nem tão pouco, de caráter temporário ou modismo (como Rádio, TVs, Jornais, etc), mas aprendida e difundida pela tradição - permanente e dinâmica - fruto da vivência diária, familiar e comunitária, no tempo e no espaço (ROCHA, 1996, p. 23).

Sabendo que os sujeitos não possuem puramente apenas uma dentre as três formas, mas que elas se misturam entre si, a cultura como um todo é primordial para a Pedagogia da Roda, mas o interesse maior centra-se na cultura popular adquirida pelos integrantes da roda. A cultura erudita e a cultura de massa podem ser negadas ou não acessadas por algumas pessoas, mas a cultura popular comumente chega a todos, por isso o interesse maior por ela.

Ao considerar cultura, deve-se prestar atenção também na cultura do próprio jovem, lembrando que "os jovens constituem culturas juvenis que thes dão uma identidade como jovens" (DAYRELL, 2007, p. 1110); esta cultura que identifica o grupo é considerada por Tião Rocha e pelo CPCD exatamente como "[...] esta rede de relações, processos e interações, que forma um padrão ou um desenho, definidor da identidade da comunidade ou grupo social" (ROCHA, 1996, p. 08). Porém, são inúmeros os casos de jovens "destituídos por experiências sociais que thes impõem uma identidade subalterna, o grupo cultural é um dos poucos espaços de construção de uma autoestima" (DAYRELL, 2007, p. 1110), sendo possível perceber essa abordagem também nos trabalhos de Dayrell e Gomes (2002; 2003).

A pedagogia da roda permite que o jovem leve a todos os presentes suas contribuições, que afirme que também sabe, pois reconhece naquela roda que "[...] não há homem absolutamente inculto: o homem 'hominiza-se' expressando, dizendo o seu mundo" (FREIRE, 2015, p. 26). Também, nas palavras de Nidelcoff (1985, p. 33), “[...] não existem homens cultos ou incultos, nem com 'muita' ou 'pouca' cultura, como normalmente se diz. Existem simplesmente, homens com culturas diferentes". Ou, ainda, nas palavras de Tião Rocha (1996, p. 08), “'todo e qualquer ser humano tem cultura'. Esta é uma das poucas 'verdades absolutas' da Antropologia. Apesar dessa afirmação parecer óbvia, muita gente ainda pensa que alguns seres humanos não têm cultura. Por isso, é importante ressaltar essa 'obviedade'”. Portanto, se todos possuem 
cultura, e a matéria-prima para a aprendizagem no CPCD é a cultura, todos podem ensinar aquilo que carregam consigo.

A roda torna-se lugar de fazer educação, "assim não cabe ao professor apenas transmitir o que ele sabe ou o que já se encontra sistematizado, e sim compreender conceitos e vivências reveladas pelos alunos a partir de seu universo sociocultural" (BREGUNCl, 1996, p. 47). Ela é o espaço de compartilhamentos e aprendizagens múltiplas por parte de todos os envolvidos. Nesse entendimento, Tião Rocha (2000, p. 28) afirma que na pedagogia da roda, "[...] todos os que participam da roda são educadores, independentes da idade, altura, sexo, etc." percebendo nesse espaço, a abertura para contribuírem de forma coletiva e permanente. Nas palavras de Paulo Freire, a roda é o lugar que oportuniza ao educando "[...] participar coletivamente da construção de um saber, que vai além do saber de pura experiência, que leve em conta as suas necessidades e o torne instrumento de luta possibilitando-Ihe transformar-se em sujeito de sua própria história" (FREIRE, 1991, p. 16).

A roda impulsiona a educação, "algo que só acontece no plural" (ROCHA, 2000, p. 27). Para Tião Rocha, "não há educação no singular, pode haver ensino, mas não educação. Esta só acontece quando o 'eu' e o 'ele' estabelecem processos e relações de troca. Ela só acontece, portanto, quando o 'nós' ou o 'eles' constroem laços de parceria, conluio, troca, reciprocidade" (ROCHA, 2000, p. 27). Caso não exista esta troca de saberes, Tião Rocha entende que os interlocutores estão trocando "seis por meia dúzia", como já dizia o ditado. É o mesmo que dizer que não houve uma troca verdadeira, não existiu uma relação de educação entre os envolvidos. Apenas uma das duas partes aprendeu, ou talvez nenhuma tenha aprendido, visto que o que lhe fora ensinado não encontrou boa recepção no outro, e acabou sendo descartado, como em uma conversa qualquer.

Conscientes de não falar para o outro, mas falar com o outro (FREIRE, 1989), os jovens se reúnem. Atividade que requer alguns cuidados por parte do educador que irá mediar a roda para não correr o risco de "converter-se num bate-papo desobrigado que marcha ao gosto do acaso" (FREIRE, 1992, p. 118). Sendo só um dos desafios diante da Pedagogia da Roda, que se bem executada promove avanços nas trajetórias dos jovens que a integram. É nas rodas que: 
[...] o ouvir o outro ajuda educandos e educador a perceber que as experiências, as vivências, as opiniões e modos de ser são diferentes para cada pessoa. O outro se torna um espelho composto por muitos outros espelhos a refletir as individualidades que estão em constante formação. A valorização e o respeito a opinião do outro vão sendo então construídos por meio de trocas que se estabelecem entre educandos e educadores. Nas trocas de olhares, percepções, gestos, falas, curiosidades, medos, inseguranças, risadas... É que cada um vai significando sua identidade, percebendo-se integrante e integrador de um grupo. São também, esses momentos que possibilitam o reconhecimento da existência do eu e do outro (ZANINI; LEITE apud KONRATH, 2013, p. 28).

Esta sensação de pertencimento ao grupo é vital aos jovens, um espaço onde pode se afirmar e expressar sua identidade. Visto que "é o nível do grupo social, no qual os indivíduos se identificam pelas formas próprias de vivenciar e interpretar as relações e contradições, entre si e com a sociedade, o que produz uma cultura própria" (DAYRELL, 2003, p. 43). Deste modo, essa cultura própria não só é de extrema importância, como também é um fator motivador para a transformação política e cultural, ao entender que o jovem reconhece suas origens e conscientiza-se daquilo que teve que enfrentar até o presente momento (FREIRE, 1979). Tal participação age de forma a corroborar para mais tantas outras realizações da Pedagogia da Roda e envolvimento dos jovens.

Para além de todas estas contribuições à sociabilidade juvenil, é também na roda que se planeja a pauta de trabalho seja ela diária, semanal ou quinzenal dependendo de cada atividade e grupo. A pauta é planejada na roda para conter a contribuição de todos os participantes (ROCHA, 2000). A roda não exclui. Todas as opiniões e sugestões são valorizadas, sem a existência de exclusões, seleção ou votação, cabendo ao grupo o consentimento pelas propostas a partir da definição de prioridades (ROCHA, 2000).

Após a pauta ser realizada, é hora de partir para a sua efetivação, seja estudar algo, construir alguma coisa, se estimular com um jogo, etc. Após esta fase, ocorre a avaliação das atividades que foram anteriormente pautadas, seguido do registro da memória. É assim que finda o processo "ação-reflexão-ação" (ROCHA, 2000) até que um novo se inicie considerando as construções que emergiram dos processos anteriores. 
São estas "[...] rodas de avaliação [que] possibilitam medir os graus de envolvimento, prazer, participação, os ritmos e os tempos do aprendizado, bem-estar e crescimento do grupo" (ROCHA, 2000, p. 28). Estas avaliações ocorrem por intermédio de diferentes registros, seja ele escrito, falado, cantado, contado, desenhado, pintado, medido ou de qualquer outra forma (ROCHA, 2000). O registro possibilita ter a memória e a história do projeto, paralelamente. Atividade que permitiu ao longo dos anos a gradativa sistematização de técnicas, instrumentos e indicadores de impactos, resultados, fracassos e êxitos (ROCHA, 2000), foi o aperfeiçoamento da pedagogia da roda que permitiu a inclusão "[...] no repertório metodológico dos nossos projetos os planos de trabalho e avaliação (PTA) e os sofisticados indicadores de qualidade de projetos sociais (IQPS), [...]" (ROCHA, 2000, p. 28). Desta forma, a pedagogia da roda demonstra potencial a ser explorado além de uma atividade isolada em sala de aula.

\section{CONSIDERAÇÕES FINAIS}

A pedagogia da roda e a cultura foram aqui analisadas como fatores de garantia da aprendizagem em Araçuaí, tornando conhecida uma fração do trabalho realizado pelo CPCD. Essa pedagogia se revela como prática de compartilhamento de ideias e valorização das juventudes que participam dos projetos, sendo uma alternativa para professores que buscam outras metodologias para a construção dos processos educacionais junto aos educandos. A cultura local é valorizada, assim como a dos próprios jovens, uma tarefa desafiadora para os envolvidos e muito animadora para os estudantes. Valorizar a cultura local e individual é oferecer oportunidade ao sujeito, é convidá-lo ao protagonismo de sua história.

Elas são fundamentais para atingir a educação, proposta pelo CPCD. Porém, não atuam sozinhas: existem outras pedagogias; existem oportunidades de emprego para os/as jovens participantes dos projetos; existe a tradição que a ONG vem consolidando ao longo dos anos, tornando-se assim uma referência para os novos participantes; etc. 
A constante realização de rodas também contribui para a experiência positiva que a ONG e os jovens vivenciam nos projetos. A prática contínua possibilita os bons resultados que foram sucintamente apresentados neste estudo. Percebemos que, se vivenciada junto aos jovens, a pedagogia da roda possibilita melhores resultados, dando abertura ao processo "ação-reflexão-ação", adaptando-a as necessidades e familiarizando os participantes com a proposta.

Se pelo contrário, for aplicada em casos pontuais, em atividades isoladas com longos intervalos entre novas rodas, a possibilidade de sucesso é reduzida, visto que os jovens e educadores não estarão familiarizados com a pedagogia. Neste sentido, identifica-se que o acerto do CPCD está no desejo de praticar Paulo Freire, através da ação-reflexão-ação, ou como dizem na ONG: "paulofreirear".

Portanto, alguns questionamentos ainda permanecem relativos ao interesse dos jovens pela cultura local e na utilização do lúdico em processos educativos: como educar os jovens que não se interessam pela cultura local? Pode-se priorizar o lúdico em qualquer idade? Aguardam-se trabalhos futuros que respondam a estas e outras indagações.

\section{REFERÊNCIAS}

ARASEMPRE. O que é. Belo Horizonte, 201-?. Disponível em:

http://www.arasempre.org.br/pagina-exemplo/o-que-e. Acesso em: 18 out. 2018.

BREGUNCl, M. G. C. Construtivismo: grandes e pequenas dúvidas. Cadernos Intermédio, ano 1, v. 1. 1996.

CPCD. Histórico. Belo Horizonte: [s.n.], 200-?a. Disponível em:

http://www.cpcd.org.br/historico/

historico/. Acesso em: 18 out. 2018.

CPCD. As pedagogias do CPCD. Belo Horizonte: [s.n.], 200-?b. Disponível em: http://www.cpcd.org.br/historico/pedagogias-do-cpcd/. Acesso em: 22 abr. 2019.

DAYRELL, J. T.; GOMES, N. L. Formação de agentes culturais juvenis. In: ENCONTRO DE EXTENSÃO DA UFMG, 6., 2003, Belo Horizonte. Anais [...]. Belo Horizonte: UFMG, 2003. p. 154-157. 
DAYRELL, J; GOMES, N. L. Juventude, práticas culturais e identidade negra. Revista Palmares em Ação, n. 2, p. 18-23, 2002.

DAYRELL, J. A escola "faz" as juventudes?: reflexões em torno da socialização juvenil. Educação \& Sociedade, v. 28, n. 100, out. 2007.

DAYRELL, J. O Jovem como sujeito social. Revista Brasileira de Educação, n. 24, p. 4052, set./dez. 2003.

FREIRE, P. A Educação na cidade. São Paulo: Cortez, 1991.

FREIRE, P. A Importância do ato de ler: em três artigos que se completam. São Paulo: Autores Associados; Cortez, 1989.

FREIRE, P. Conscientização: teoria e prática da libertação, uma introdução ao pensamento de Paulo Freire.Tradução de Kátia de Mello e Silva. São Paulo: Cortez \& Moraes, 1979.

FREIRE, P. Pedagogia da autonomia. São Paulo: Paz e Terra, 1996.

FREIRE, P. Pedagogia da esperança: um reencontro com a pedagogia do oprimido. Rio de Janeiro: Paz e Terra, 1992.

FREIRE, P. Pedagogia do oprimido. São Paulo: Paz e Terra, 2015.

GUATTARI, F. Caosmose: um novo paradigma estético. Rio de Janeiro: 34, 1993.

KONRATH, R. D. (Org). Roda de conversa na e da educação infantil. São Leopoldo: Oikos, 2013.

LÉVY, P. A inteligência coletiva: por uma antropologia do ciberespaço. São Paulo, 1998.

LUNA, S. Planejamento de pesquisa: uma introdução. 2. ed. São Paulo: EDUC, 2011.

NIDELCOFF, M. T. Uma escola para o povo. Tradução João Silverio Trevisan. São Paulo: Brasiliense, 1985.

NONATO, S. P. et al. Por uma pedagogia das juventudes. In: DAYRELL, J. (Org). Por uma pedagogia das juventudes: experiências educativas do Observatório da Juventude da UFMG. Belo Horizonte: Mazza Edições, 2016, p. 249-304.

PAIS, J. M. A Juventude como fase de vida: dos ritos de passagem aos ritos de impasse. Saúde e Sociedade. São Paulo, v.18, n.3, p.371-381, 2009.

PORVIR. Relatório de resultados: nossa escola em (re)construção. [S.I.:s.n.], 2016.

Disponível em: https://bit.ly/2fB81cr. Acesso em: 25 maio 2018. 
RICHARDSON, R. J. Pesquisa social: métodos e técnicas. São Paulo: Atlas, 1999.

ROCHA, S. A pedagogia da roda. Boletim Espacio para la infância. n. 13, p. 24-29, 2000.

ROCHA, T. Folclore: roteiro de pesquisa. Belo Horizonte: SENAC, 1996.

ROITMAN, I.; RAMOS, M. N. A Urgência da educação. São Paulo: Moderna, 2011. Disponível em: https://bit.ly/2WbZqRE. Acesso em: 23 maio 2018.

RUIZ, J. Á. Metodologia científica: guia para eficiência nos estudos. 13. ed. São Paulo: Atlas, 1985.

SUÁREZ, D.; OCHOA, L. La documentación narrativa de experiencias pedagógicas: una estrategia para la formación de docentes. Buenos Aires: Ministerio de Educación, Ciencia y Tecnología, 2005. 